\title{
Race and Social Problems
}

\author{
Edward Telles
}

Published online: 16 March 2012

(C) Springer Science+Business Media, LLC 2012

Latinos represent one of the fastest growing population segments in the United States. The 50 million or so Latinos in the United States, which comprise about $15 \%$ of the US population, are here to stay and these numbers will continue to grow. As a group, they have now surpassed the African American population. Up to about 1990, Latinos or Hispanics were mostly geographically confined to the US. Southwest and a handful of places outside that region (New York, Chicago and South Florida), but they now reside throughout the United States. Despite stereotypes about Latinos as immigrants, most are actually born in the United States including those whose families have been here for several generations. Nonetheless, there is a large immigrant component, including many whom are unauthorized, which feeds Latino population growth and complicates American attitudes and perceptions about the Latino population.

Latinos are a diverse group of many nationalities, but the Mexican segment comprises fully $65 \%$ of the entire Latino population and is among the most disadvantaged. Moreover, Mexicans comprise about half of the entire US undocumented population, they have the longest and largest immigration trajectory and they have been largely concentrated in the Southwest US, though that is changing as Mexican immigrants are increasingly populating new desinations, especially in the South. For these reasons several of the articles focus on that population. Because of the wide diversity of the Latino population, we are thus careful to avoid generalization.

We use the terms Latino and Hispanic interchangeably throughout this paper, even though technically they may refer to somewhat different populations. Hispanic may

E. Telles $(\bowtie)$

Princeton University, Princeton, NJ, USA

e-mail: etelles@princeton.edu include the small number of Spanish people while excluding the small Brazilian population while Latino does the inverse. Perhaps with these tiny exceptions, they refer to virtually the same populations. An important issue is that this pan-ethnic label was crafted by the Spanish language media, businesses, the US Census and political leaders, as a way of simplifying the categorization of a population (for various reasons) that was mostly known and continues to mostly identify by its national origins (Mora, in progress). Though there are certainly objections to the use of either term, the authors of these chapters tend to favor one or the other, a decision they may have made for various reasons.

Whether you call them Latinos or Hispanics, Americans often voice strong feelings about their presence. Pundits like Samuel Huntington and Patrick Buchanan have written strongly against immigration from Latin America. They argue that Latin Americans, particularly Mexicans, are unwilling to assimilate and they therefore represent a serious threat to the American nation. Their followers are numerous, as a scan at the immigration blogs and some mainstream media reveal. Moreover, an anti-immigration brand of politics has resulted in stringent laws against the undocumented, which end up affecting the larger Latino population in various ways, as the cases of Arizona and Alabama vividly show. On the other side of public opinion, many Americans tout the United States as a nation of immigrants, in which successive waves made contributions to American culture, its economy and its democracy. Employers, today as in the past, clearly see immigrants as fueling the economy in many sectors. Latinos, who comprise the majority of the current wave, are seen as no different from previous immigrants. Unfortunately, there are many Americans on either side of a polarized debate and not enough that have an informed or nuanced opinion. Moreover, opinions about immigration and Latinos are 
largely based on perceptions and rarely on scientific data and analysis.

The articles in this volume represent the work of leading analysts of the Latino population in the United States and each of the chapters addresses important social problems facing that population. At the current moment, with the Presidential campaign off to a start, political candidates are concerned about how the large Latino population will vote. Will they vote collectively? How will they respond to positions they take on various issues, especially immigration control. What about social entitlements, education spending and jobs creation? Republican candidates campaigning for votes in states with large Hispanic populations are careful in their views regarding immigration and challenge the views of other candidates who have made immigration restriction a clear part of their agenda.

The journal title (Race and Social Problems) makes race a central theme that merits at least some clarification when applied to Latinos. First of all, we assume race in a sociological sense where people perceive races, often imparting them with social consequences, while we agree with the consensus position that race does not exist in the biological sense. Having said that, the question of whether Latinos are a race is certainly a complicated one since definitions of race vary widely and Americans understand race generally as an innate physical quality (essentialized) and mostly as a distinction between European- and African Americans (Morning 2011). However, race is not so clear for other groups. Certainly, the Latino population is very racially diverse itself in the physical sense but Americans often perceive them as a group apart from whites, blacks, Asians and others which social scientists have referred to as racialization. The ideas of Latinos as a race for many Americans are based on real or perceived culture or physical differences. The US Census, a barometer of racial thinking in America, allows Latinos/Hispanics to define themselves as belonging to any race but at the same time it publishes reports that list Latinos, no matter how they identified themselves by race, as separate from other racial groups, essentially treating them as a race.

Following on the other part of the title of this journal (Race and Social Problems), we address social problems that are central to Latino populations and the communities around them. The chapters in this volume are on immigration; education, including the high school drop out rate and higher education; the racialization of Latinos; crime and punishment and fertility. As Latinos settle in the United States, they develop a particular set of social problems that are often the result of societal structures such as a broken down immigration system and an inequitable educational system. Despite the often sunny accounts of the state of Latino America, we identify and examine important challenges that face Hispanics. Given their growing importance in American society, they are challenges facing the country as well.

Relatedly, several of the chapters in this volume address policy formulations that may ultimately affect the nature of their integration. Unfortunately, many policies are often designed based on perceptions and without regard to facts or careful social science analysis. This is probably clearest in the heated immigration debate, and its consequences for other areas of social and economic policy such as education and crime control, which we examine in this journal. Implementing policies without effective diagnosis is often at the peril of a better American future or even of Latinos themselves. Policy prescriptions based on a reading of facts, which are often complex, are generally avoided by both optimists (everything is fine with immigration and pointing out problems feeds into the restrictionist agenda) and pessimists (we cannot afford them, problems with them are obvious and any problems are due to these individual's cultural deficiencies).

\section{The Chapters}

Most of the authors in this volume are social demographers. All of them (or at least the senior authors) have extensive experience in research about the Latino population. They are all quantitative researchers, which means that measurement issues are central to their work. Oftentimes, the basic assumptions we make are based on erroneous information, as these chapters will show. This is definitely true for immigration but it is also apparent regarding fertility and the high school drop out rate, which are two areas that are be fraught with measurement issues as different numbers are bandied about. As new Latino groups immigrate to the United States, the largely Mexican research focus has begun to change.

The first article by Douglas S. Massey and Karen A. Pren examines immigration and the incipient formation of a new Latino underclass. The authors provide an important overview of Latino and especially Mexican immigration and its contribution to the US population. In particular, they quantitatively illustrate the rise of an undocumented population occurring in response to US immigration legislation and policies. They argue that a growing policy emphasis on border apprehensions in particular have produced a selfperpetuating cycle of conservative reaction that demands even more border apprehensions, which then produces even more conservative and anti-immigrant reactions, etc. The authors argue that rather than dealing with immigration in a more productive way, politicians have found it more useful to construct a Latino threat narrative that continues to feed more anti-immigrant hysteria and still greater militarization of the border while persistently avoiding policies that seek to 
integrate these immigrants and their children, ultimately creating a new underclass in the United States.

The second article, by Emilio A. Parrado and Chenoa Flippen, challenges official population statistics on Hispanic fertility. A popular contention is that Hispanics tend to have many children, which impedes their assimilation and sets them apart from the American mainstream. In fact, opponents of immigrations frequently cite official statistics showing that Hispanics average higher fertility than other Americans. Though official fertility statistics for US Hispanics are not as high as often claimed and the producers of these statistics are unlikely to hold an anti-immigrant agenda, they (unintentionally) overstate the reality of Hispanic fertility and thus contribute to nativist fears. The discrepancy stems mainly from misunderstanding the fertility contribution of immigrants. Parrado and Flippen show that by drawing on assumptions about a non-mover population, standard fertility measures miss the fact that migration disrupts the pattern of childbearing inflating fertility rates to the point where they no longer correspond with family size. Moreover, they show that the contribution of immigrant fertility to Hispanic population growth is much lower than anticipated since only a fraction of the fertility of immigrant women occurs in the US and part of their pre-migration fertility does not cross the border.

The third chapter by Stowell, Martinez and Cancino examines incarceration patterns and homicide rates involving Latinos, based on empirical evidence. Certainly, nativists have raised their concerns, to say the least, about Latino crime based on anecdotes and news stories but actual crime rates are rarely brought into the debate. These authors show that homicide rates declined at the same time that Latino immigration grew. Moreover, contrary to the claims that the US-Mexico border is out of control due to the "hordes of lawless and undocumented" border-crossers, these authors find no support that border proximity affects homicide levels, either over time or across space. Instead, they find lower homicide rates closer to the border and where there are more immigrants. Also, consistent with the first two chapters of this volume, the immigration system itself has become criminalized, which further raises anti-immigrant and anti-Latino hysteria.

The fourth chapter, by Vilma Ortiz and Edward Telles, examines the issue of racial identity and discrimination among Mexican Americans. Although Mexicans and other Latinos have been compared to low status immigrants like Italians, who were eventually fully integrated in American society, their study shows that Mexican Americans whose immigrant ancestors came at the same time as Italians, have not been similarly integrated. Third and fourth generation Mexican Americans experience racial discrimination and stereotyping as well as see themselves as racially distinct. Moreover, Mexican Americans have about the lowest educational achievement rates of major race/ethnic groups in the United States, even three or four generations since their immigrant ancestors. These findings suggest that these latter generation Mexican Americans have not been as successful as Italian Americans in successfully integrating into American society, largely because they continue to have racialized experiences. In contrast, Italian American integration was facilitated by being able to integrate into the American (white) mainstream.

Harris and Tienda focus on higher education, particularly on the admission of Latinos at the Texas flagship universities. They find that the rate of college applications is much lower for Hispanics than for the white population, which reflects the poor state of Latino education in Texas and a culture of not applying to elite universities in the state. Moreover, applications increase when affirmative action programs are in place to encourage Latino enrollment. The denial of policies that encourage college going for Latinos in states like Texas with such large and growing Latino populations, represent a cost not only to Hispanics themselves but also to a well functioning economy that requires an educated labor force and the development of a diverse and democratic society.

Finally, Saenz and Siordia examine the high school drop out rate for the Mexican American population, which has the lowest rates of educational attainment rate in the United States among major race/ethnic groups. They first examine the measurement issues that have beguiled calculation of the high school dropout rate and have led to inconsistent conclusions. Once establishing the best metric for its calculation, the authors analyze the factors that account for variations in the Mexican American drop out rate across the country. They find that low levels of education are most likely to be reproduced in those places in which older age cohorts have also had high dropout rates. As Saenz and Siorda note, as do the previous two articles, education is the critical area needed for the group to shed their status as a low status group. As they point out, policies are urgently needed that include rather than push these students out of the educational system.

Together, the papers in this volume illustrate the importance of understanding the complex issues that the United States faces as it confronts its growing Latino population. These include the looming issues of immigration, education and crime. But even before we can properly analyze these issues, these papers also show that we need to improve data collection and analysis to better understand important issues like fertility, the high-school dropout rate and crime. As the population grows, policies need to consider how to better include Latinos as integral parts of American society. In states like Texas and California, where Latinos now account for large proportions of the total population, more equitable and improved public 
education as well as improvements in other institutions for social integration will improve Latino lives as well as those state's general economy. Currently, Latinos are important players in the current electoral campaigns, which unfortunately have become highly polarized on some of the very issues that are important to them. Indeed, the near-term fate of successful integration policies for Latinos and others may hinge largely on this election. Moreover, the research in this volume has largely shown that to disregard positive integration policies that may overcome underlying challenges that face the Latino population comes at the peril of not only Latinos themselves but also of American society in general.

\section{References}

Mora, G. Cristina De Muchos. (in progress). Uno: The Institutionalization of Latino Panethnicity - Book Manuscript

Morning, Ann. (2011). The nature of race: How scientists think and teach about human difference. Berkeley: University of California Press. 